\title{
Receipt of Guideline-Concordant Care Among Older Women With Stage I-III Breast Cancer: A Population-Based Study
}

\author{
Traci LeMasters, $\mathrm{PhD}^{\mathrm{a}, \mathrm{b}}$; S. Suresh Madhavan, $\mathrm{MBA}, \mathrm{PhD}^{\mathrm{a}}$; Usha Sambamoorthi, $\mathrm{PhD}^{\mathrm{a}}$; \\ Hannah W. Hazard-Jenkins, MD ${ }^{\mathrm{b}, \mathrm{c}}$; Kimberly M. Kelly, PhDa,b; and Dustin Long, PhD,e
}

\begin{abstract}
Background: This study examined receipt of guideline-concordant care (GCC) according to evidence-based treatment guidelines and quality measures and specific types of treatment among older women with breast cancer. Patients and Methods: A total of 142,433 patients aged $\geq 66$ years diagnosed with stage I-III breast cancer between 2007 and 2011 were identified in the SEER-Medicare linked database. Algorithms considering cancer characteristics and the appropriate course of care as per guidelines versus actual care received determined receipt of GCC. Multivariable logistic regression estimated the likelihood of GCC and specific types of treatment for women aged $\geq 75$ versus 66 to 74 years. Results: Overall, $39.7 \%$ of patients received GCC. Patients diagnosed at stage II or III, with certain preexisting conditions, and of nonwhite race were less likely to receive GCC. Patients with hormone-negative tumors, higher grade tumors, and greater access to oncology care resources were more likely to receive GCC. Patients aged $\geq 75$ years were approximately $40 \%$ less likely to receive GCC or adjuvant endocrine therapy, $78 \%$ less likely to have any surgery, $61 \%$ less likely to have chemotherapy, and about half as likely to have radiation therapy than those aged 66 to 74 years. Conclusions: Fewer than half of older women with breast cancer received GCC, with the lowest rates observed among the oldest age groups, racial/ethnic minorities, and women with later-stage cancers. However, patients with more aggressive tumor characteristics and greater access to oncology resources were more likely to receive GCC. Considering that older women have the highest incidence of breast cancer and that many are diagnosed at stages requiring more aggressive treatment, efforts to increase rates of earlier stage diagnosis and the development of less toxic treatments could help improve GCC and survival while preserving quality of life.
\end{abstract}

\section{Background}

More than 50 years of research has guided the development of evidence-based treatment guidelines for breast cancer, including those published by NCCN., ${ }^{1,2}$ Although the course of treatment for each woman is primarily determined by her tumor characteristics and extent of disease, multiple treatment pathways exist that are dependent on patient characteristics and preferences. However, not all patients receive guideline-concordant

\footnotetext{
aDepartment of Pharmaceutical Systems and Policy, School of Pharmacy, bWest Virginia University Cancer Institute, 'Department of Medical Education, School of Medicine, and dDepartment of Biostatistics, School of Public Health, West Virginia University, Morgantown, West Virginia; and eDepartment of Biostatistics, School of Public Health, University of Alabama at Birmingham, Birmingham, Alabama.

Submitted February 17, 2016; accepted for publication January 3, 2018.

The authors have disclosed that they have no financial interests,

arrangements, affiliations, or commercial interests with the manufacturers of any products discussed in this article or their competitors.
}

care (GCC). Vulnerable populations, such as racial and ethnic minorities or those who are socioeconomically disadvantaged, are more likely to experience treatment disparities. ${ }^{3-7}$ Independent of these characteristics, older women are less likely to receive GCC due to increasing age and declining health and functional status associated with older age. ${ }^{6,8,9}$ The NCCN Clinical Practice Guidelines in Oncology (NCCN Guidelines) for Breast Cancer contain 2 age-based treatment concessions. The

Author contributions: Study concept: LeMasters, Madhavan. Study design: All authors. Data analysis: LeMasters, Sambamoorthi, Hazard-Jenkins. Data interpretation: All authors. Manuscript preparation: LeMasters, Madhavan, Sambamoorthi. Critical revision: Madhavan, Sambamoorthi, HazardJenkins, Kelly, Long.

Correspondence: Traci LeMasters, PhD, Department of Pharmaceutical Systems and Policy, Robert C. Byrd Health Sciences Center, School of Pharmacy, West Virginia University, P.O. Box 9500, Morgantown, WV 26506-9500. Email: tlemasters@hsc.wvu.edu 
LeMasters et al

first is the omission of radiation therapy (RT) following breast-conserving surgery (BCS) for patients aged $\geq 70$ years with stage I, estrogen receptor (ER) positive breast cancer and that they should receive adjuvant endocrine therapy (AET) based on the CALGB C9343 trial findings. ${ }^{2,10,11}$ The second is the recommendation that the decision to treat women aged $>70$ years with chemotherapy be made on a case-by-case basis, considering patient preferences, health, and risks, citing insufficient evidence for this age group. ${ }^{2,12}$ Guidelines note that older women who received chemotherapy in trial studies experienced similar survival outcomes but had an increased risk for side effects and treatment-related mortality. ${ }^{13,14}$

Despite flexibility in treatment guidelines, treatment disparities reported by previous studies raise concern that older women are undertreated more frequently than warranted. Recent studies have reported that among women aged $\geq 65$ years, $21 \%$ to $29 \%$ did not receive RT following BCS for earlystage breast cancer regardless of their ER status, ${ }^{4,15}$ $67 \%$ with lymph node-positive disease did not receive chemotherapy, ${ }^{9} 50 \%$ did not receive trastuzumab, ${ }^{16}$ and $17 \%$ to $40 \%$ did not receive AET when indicated. ${ }^{5}$ Moreover, age and comorbidity have been found to be the strongest predictors of treatment, irrespective of clinical indications. ${ }^{17-20}$ These findings are of particular concern considering that women aged $\geq 65$ years represent $43 \%$ of newly diagnosed breast cancer cases ${ }^{21}$ and that undertreatment is associated with worse disease-specific survival for many older patients. ${ }^{15,17,20}$

Although undertreatment is commonly reported among older women with breast cancer, it is difficult to discern how inappropriate or problematic this is if the treatment is in accordance with evidencebased treatment guidelines that provide age-based treatment considerations, depending on individual circumstances. Therefore, the extent to which older women with invasive breast cancer receive GCC, considering all available treatment options, remains unknown. Bearing these thoughts in mind, the goal of this study was to determine US population-based estimates of the prevalence and associations with GCC for breast cancer among older women, as well as receipt of specific types of treatments using the US population-based SEER-Medicare data.

\section{Patients and Methods}

\section{Data Source and Cohort Definition}

The SEER-Medicare linked database was created in a collaborative effort by the NCI and Centers for Medicare \& Medicaid Services. SEER data are collected from 17 tumor registries representing 26\% of the US population, and are successfully matched to Medicare enrollment records for $94 \%$ of patients aged $\geq 65$ years. ${ }^{22}$ SEER-Medicare data contains information about date of diagnosis, cancer site, stage, tumor characteristics, treatment, healthcare use, patient enrollment and eligibility, selected demographic characteristics, and vital status information. Medicare claims are available for Part A (inpatient), Part B (outpatient), and Part D (prescription drug) services. ${ }^{23}$ County and state identifiers were used to link SEER-Medicare data to the US Department of Health \& Human Service's 2009 Area Resource File (ARF) to identify the area-level health resources. ${ }^{24}$

We identified 431,212 women aged $\geq 66$ years diagnosed with breast cancer as their first or only primary tumor between January 1, 2007, and December 31,2011 . We excluded women without a pathologic diagnosis $(n=9,954)$ and those diagnosed with breast cancer at death or autopsy $(n=30)$; who died within 366 days of diagnosis $(n=23,729)$; diagnosed with stage 0 or stage IV disease $(n=105,189)$; not continuously enrolled in Medicare Parts A and B fee-for-service programs for 12 months before and after diagnosis $(n=9,469)$; not continuously enrolled in Medicare Part D services for 4 months before diagnosis and 12 months after diagnosis $(n=124,231)$; enrolled in a health maintenance organization plan during the 12 months before and after diagnosis $(n=14,542)$; and whose records were missing tumor size $(n=484)$ and surgeon specialty $(n=1,151)$. The final analytic cohort consisted of 142,433 patients (Figure 1).

\section{Dependent Variables}

The primary outcome was receipt of GCC, defined as treatment, including surgery, RT, chemotherapy, and AET, received according to the NCCN Guidelines for Breast Cancer, Version 1.2009. ${ }^{25}$ Measures assessed by this study remained unchanged in previous and later versions of the guidelines published during the cohort study period. Initiation of chemotherapy within 120 days of diagnosis, when indicated, as specified by the joint ASCO/NCCN quality measures, ${ }^{26}$ and receipt of $\mathrm{ER}$ and progesterone receptor $(\mathrm{PR})$ 


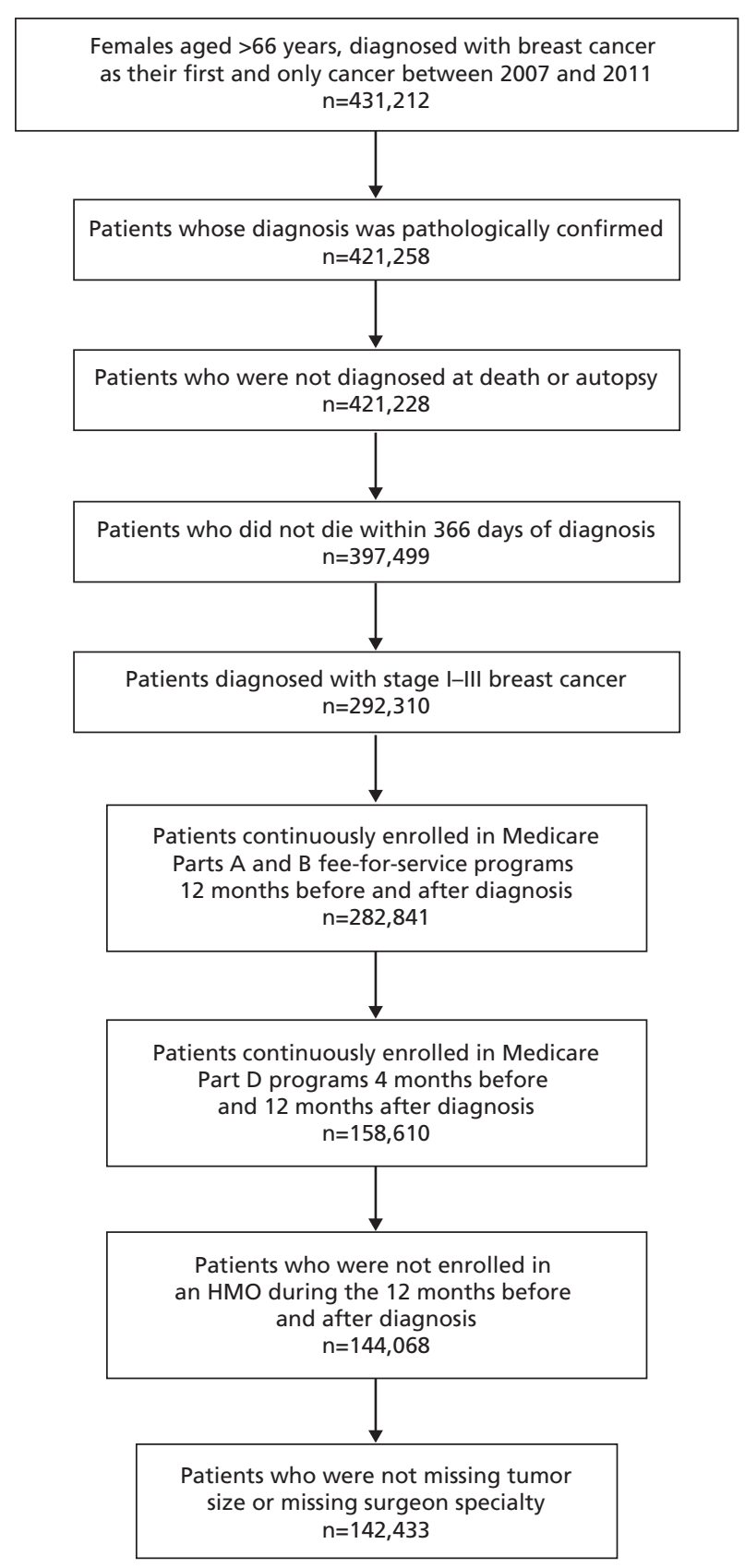

Figure 1. Flow diagram for study cohort selection. Abbreviation: HMO, health maintenance organization.

testing were also included in the definition of GCC. Hormone receptor testing was ascertained using a previously described method that considers documentation of a "positive," "negative," or "borderline" ER and PR status as an indication that hormone receptor testing was conducted, and an "unknown" or "missing" status as an indication that testing was not conducted. ${ }^{27}$ Receipt of GCC was determined using algorithms that compared the correct course of care with the actual care received (Figure 2). As stated in the NCCN Guidelines, omission of RT after BCS if the patient was aged $\geq 70$ years; had stage I, ER-positive breast cancer; and received AET was considered GCC. Omission of chemotherapy, when indicated, was considered GCC among women aged $>70$ years. If chemotherapy was received, then time to initiation of chemotherapy was assessed. Surgery, RT, chemotherapy, and AET were ascertained by identifying ICD-9 diagnostic and procedure codes and Healthcare Common Procedure Coding System/ Current Procedural Terminology codes for generic drug names (see supplemental eTable 1, available with this article at JNCCN.org).

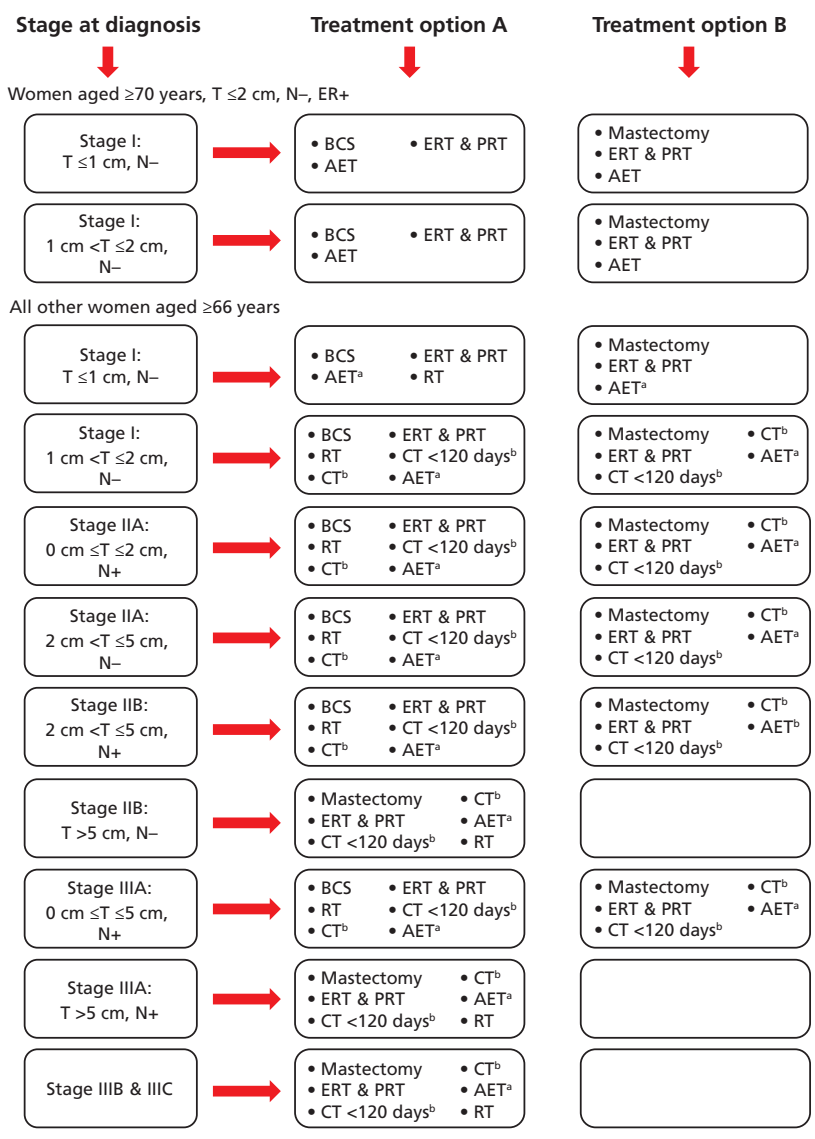

Figure 2. Guideline-concordant treatment options by tumor size and lymph node status.

Abbreviations: AET, adjuvant endocrine therapy; BCS, breast-conserving surgery; $\mathrm{CT}$, chemotherapy; ER, estrogen receptor; ERT, estrogen receptor testing; $\mathrm{N}$, nodal status; $\mathrm{PR}$, progesterone receptor; PRT, progesterone receptor testing; $\mathrm{RT}$, radiation therapy; $\mathrm{T}$, tumor size. ${ }^{a} A E T$ recommended when breast tumors are ER- and/or PR-positive. ${ }^{b}$ Recommended that, for women aged $>70$ years, the decision to treat with chemotherapy should be made on an individual patient basis. 
The secondary outcome was receipt of individual tests and treatments: ER testing, PR testing, BCS, mastectomy, RT, chemotherapy, initiation of chemotherapy within 120 days of diagnosis, and AET when indicated.

\section{Independent Variables}

Independent variables included year of diagnosis, age, preexisting chronic conditions, frequency of primary care provider (PCP) visits, clinical prognostic factors, oncology care resources, and demographic characteristics. Specific preexisting chronic conditions prevalent among older individuals examined were anxiety, depression, dementia, arthritis, osteoporosis, diabetes, hypertension, hyperlipidemia, heart disease, stroke, and chronic obstructive pulmonary disease, identified using methods described by the Working Group on Health Outcomes for Older Persons With Multiple Chronic Conditions. ${ }^{28}$ Frequency of PCP visits was calculated by counting the number of unique PCP claim dates recorded 1 year before diagnosis in the physician claims file and dividing by the lower and upper 50 th percent median cutoff (low, high). Clinical prognostic factors examined were stage at diagnosis, tumor size, lymph node status, ER status, PR status, and tumor grade. Measures of oncology care resources were the density (low vs high) of area-level mammography screening centers and oncology treatment centers relative to each woman's location of residence using data from the ARF, and were then categorized by the lower and upper 50th percent median cutoff. Surgeon specialty was assessed using provider specialty claims codes 02 and 49 (general) and 83, 90, 91, and 98 (oncology) from the physician claims file variable "hcfaspec" to determine the type of surgeon seen (general only, oncology only, both). Demographic characteristics examined were race/ethnicity, marital status, 2010 Census measure of education and annual income, and metropolitan status.

\section{Statistical Analysis}

Pearson and Mantel-Haenszel chi-square tests were used to compare the proportions of patients receiving GCC. Multivariable logistic regression models estimated the adjusted odds of receiving GCC (yes vs no), adjusting for all covariates. A secondary analysis was performed to further investigate the association of age of receipt of GCC and specific tests and treatments, controlling for all other covariates using multivariable logistic regression models. Age was dichotomized by women aged $\geq 75$ years versus 66 to 74 years, because findings from the primary analysis showed a significant decrease in GCC after 74 years of age. Parameter estimates are presented as adjusted odds ratios (AORs) with their corresponding 95\% CIs; $P \leq .05$ was considered statistically significant. All analyses were conducted using SAS 9.4 (SAS Institute Inc.). This study was approved for exemption by the West Virginia Institutional Review Board.

\section{Results}

\section{Cohort Characteristics}

Patient characteristics are presented in supplemental eTable 2. Most were aged $>80$ years at diagnosis, white, diagnosed at stage I, lymph node-negative, ER-positive, and diagnosed with hypertension and hyperlipidemia. Most patients received BCS (60.8\%), RT (57.4\%), and AET (49.7\%). Overall, $39.7 \%$ received GCC.

\section{Receipt of GCC}

Rates of GCC were highest among women aged 70 to 74 years and lowest for those aged $\geq 80$ years ( $50.5 \%$ vs $28.1 \% ; P<.001$; supplemental eTable 2 ). Lower rates of GCC were observed among women with preexisting depression, dementia, arthritis, diabetes, or heart disease compared with those without these conditions. Women diagnosed at stage I had higher rates of GCC than those diagnosed at stages II and III (42.0\% vs $37.2 \%$ and $36.9 \%$, respectively; $P<.001$ ), as did women with hormone-negative and higher-grade tumors. Women treated by an oncology surgeon or both an oncology and general surgeon had higher rates of GCC than women treated by a general surgeon $(37.9 \%$ and $43.3 \%$ vs $19.2 \%$; $P<.001)$. White women had higher rates of GCC than those who were black, Hispanic/Latino, and other races $(41.8 \%$ vs $32.5 \%, 36.5 \%, 37.2 \%$, respectively; $\mathrm{P}<.001)$. Multivariable regression analyses confirmed findings of the bivariate analysis (Table 1). Compared with women aged 66 to 69 years, those aged $\geq 80$ years were approximately half as likely to receive GCC (AOR, 0.52; 95\% CI, 0.51-0.54). Women with hypertension (AOR, 1.15; 95\% CI, 1.12-1.19) and stroke (AOR, 1.45; 95\% CI, 1.381.52 ) were more likely to receive GCC than those 
Guideline-Concordant Care

\begin{tabular}{|c|c|c|c|}
\hline & \multicolumn{3}{|c|}{ Concordant vs Discordant } \\
\hline & AOR & $95 \% \mathrm{Cl}$ & $P$ Value \\
\hline \multicolumn{4}{|c|}{ Year of diagnosis } \\
\hline 2007 & 1.00 & Ref & \\
\hline 2008 & 1.08 & $1.04-1.13$ & $<.001$ \\
\hline 2009 & 1.07 & $1.03-1.11$ & $<.001$ \\
\hline 2010 & 1.39 & $1.33-1.45$ & $<.001$ \\
\hline 2011 & 1.44 & $1.38-1.49$ & $<.001$ \\
\hline \multicolumn{4}{|c|}{ Age at diagnosis, $y$} \\
\hline $66-69$ & 1.00 & Ref & \\
\hline $70-74$ & 1.48 & $1.43-1.53$ & $<.001$ \\
\hline $75-79$ & 1.01 & $0.97-1.05$ & \\
\hline$\geq 80$ & 0.52 & $0.51-0.54$ & $<.001$ \\
\hline \multicolumn{4}{|c|}{ Health factors } \\
\hline \multicolumn{4}{|c|}{ PCP visits } \\
\hline Low & 1.00 & Ref & \\
\hline High & 1.16 & $1.13-1.19$ & $<.001$ \\
\hline \multicolumn{4}{|l|}{ Anxiety } \\
\hline Yes & 1.08 & $1.03-1.13$ & .001 \\
\hline No & 1.00 & Ref & \\
\hline \multicolumn{4}{|c|}{ Depression } \\
\hline Yes & 0.48 & $0.46-0.51$ & $<.001$ \\
\hline No & 1.00 & Ref & \\
\hline \multicolumn{4}{|c|}{ Dementia } \\
\hline Yes & 0.68 & $0.63-0.72$ & $<.001$ \\
\hline No & 1.00 & Ref & \\
\hline \multicolumn{4}{|l|}{ Arthritis } \\
\hline Yes & 0.88 & $0.85-0.90$ & $<.001$ \\
\hline No & 1.00 & Ref & \\
\hline \multicolumn{4}{|c|}{ Osteoporosis } \\
\hline Yes & 0.96 & $0.92-1.00$ & .032 \\
\hline No & 1.00 & Ref & \\
\hline \multicolumn{4}{|l|}{ Diabetes } \\
\hline Yes & 0.79 & $0.77-0.81$ & $<.001$ \\
\hline No & 1.00 & Ref & \\
\hline \multicolumn{4}{|c|}{ Hypertension } \\
\hline Yes & 1.15 & $1.12-1.19$ & $<.001$ \\
\hline No & 1.00 & Ref & \\
\hline \multicolumn{4}{|c|}{ Hyperlipidemia } \\
\hline Yes & 0.91 & $0.88-0.93$ & $<.001$ \\
\hline No & 1.00 & Ref & \\
\hline \multicolumn{4}{|c|}{ Heart disease ${ }^{a}$} \\
\hline Yes & 0.77 & $0.75-0.80$ & $<.001$ \\
\hline No & 1.00 & Ref & \\
\hline \multicolumn{4}{|l|}{ Stroke } \\
\hline Yes & 1.45 & $1.38-1.52$ & $<.001$ \\
\hline No & 1.00 & Ref & \\
\hline \multicolumn{4}{|c|}{ Chronic obstructive pulmonary disease } \\
\hline Yes & 0.99 & $0.95-1.03$ & .657 \\
\hline No & 1.00 & Ref & \\
\hline \multicolumn{4}{|c|}{ Clinical prognostic factors } \\
\hline \multicolumn{4}{|c|}{ Stage at diagnosis } \\
\hline 1 & 1.00 & Ref & \\
\hline II & 0.64 & $0.61-0.68$ & $<.001$ \\
\hline III & 0.66 & $0.61-0.71$ & $<.001$ \\
\hline
\end{tabular}

\begin{tabular}{|c|c|c|c|}
\hline & \multicolumn{3}{|c|}{ Concordant vs Discordant } \\
\hline & AOR & $95 \% \mathrm{Cl}$ & $P$ Value \\
\hline \multicolumn{4}{|l|}{ Tumor size, $\mathrm{cm}$} \\
\hline$<1$ & 1.00 & Ref & \\
\hline 1 to $<2$ & 0.79 & $0.77-0.82$ & $<.001$ \\
\hline $2-5$ & 1.43 & $1.35-1.51$ & $<.001$ \\
\hline$>5$ & 0.23 & $0.21-0.26$ & $<.001$ \\
\hline \multicolumn{4}{|l|}{ Lymph nodes } \\
\hline Positive & 0.99 & $0.94-1.03$ & .585 \\
\hline Negative & 1.00 & Ref & \\
\hline \multicolumn{4}{|l|}{ ER status } \\
\hline Positive & 1.00 & Ref & \\
\hline Negative & 2.58 & $2.46-2.70$ & $<.001$ \\
\hline Borderline/Unknown & 0.0 & $0.00-2.00$ & .715 \\
\hline \multicolumn{4}{|l|}{ PR status } \\
\hline Positive & 1.00 & Ref & \\
\hline Negative & 1.15 & $1.11-1.20$ & $<.001$ \\
\hline Borderline/Unknown & 0.28 & $0.24-0.31$ & $<.001$ \\
\hline \multicolumn{4}{|l|}{ Tumor grade } \\
\hline Well-differentiated & 1.00 & Ref & \\
\hline $\begin{array}{l}\text { Moderately } \\
\text { differentiated }\end{array}$ & 1.27 & $1.23-1.31$ & $<.001$ \\
\hline Poorly differentiated & 1.51 & $1.45-1.57$ & $<.001$ \\
\hline $\begin{array}{l}\text { Undifferentiated/ } \\
\text { Unknown }\end{array}$ & 0.59 & $0.56-0.63$ & $<.001$ \\
\hline \multicolumn{4}{|l|}{ Oncology care resources } \\
\hline \multicolumn{4}{|c|}{ Mammography screening centers } \\
\hline Low & 1.00 & Ref & \\
\hline High & 1.63 & $1.43-1.84$ & $<.001$ \\
\hline \multicolumn{4}{|l|}{ Oncology treatment centers } \\
\hline Low & 1.00 & Ref & \\
\hline High & 0.96 & $0.84-1.08$ & .476 \\
\hline \multicolumn{4}{|c|}{ Specialty of treating surgeons } \\
\hline General & 1.00 & Ref & \\
\hline Oncology & 1.62 & $1.52-1.73$ & $<.001$ \\
\hline General \& oncology & 3.02 & $2.90-3.15$ & $<.001$ \\
\hline \multicolumn{4}{|l|}{ Demographic characteristics } \\
\hline \multicolumn{4}{|l|}{ Race/Ethnicity } \\
\hline White & 1.00 & Ref & \\
\hline Black & 0.60 & $0.58-0.62$ & $<.001$ \\
\hline Hispanic/Latino & 0.70 & $0.65-0.75$ & $<.001$ \\
\hline Other & 0.57 & $0.53-0.61$ & $<.001$ \\
\hline \multicolumn{4}{|l|}{ Education } \\
\hline$<15 \%$ college degree & 1.04 & $1.01-1.07$ & .005 \\
\hline$\geq 15 \%$ college degree & 1.00 & Ref & \\
\hline \multicolumn{4}{|l|}{ Annual income } \\
\hline$\leq \$ 35,000$ & 1.03 & $1.00-1.06$ & .037 \\
\hline$>\$ 35,000$ & 1.00 & Ref & \\
\hline \multicolumn{4}{|l|}{ Married/Partnered } \\
\hline Yes & 1.00 & Ref & \\
\hline No & 1.02 & $1.00-1.05$ & .079 \\
\hline \multicolumn{4}{|l|}{ Region } \\
\hline Metropolitan & 0.69 & $0.66-0.73$ & $<.001$ \\
\hline Nonmetropolitan & 1.00 & Ref & \\
\hline
\end{tabular}

Abbreviations: AOR, adjusted odds ratio; ER, estrogen receptor; PCP, primary care physician; PR, progesterone receptor. ancludes coronary artery disease and cardiac arrhythmia.

without these conditions. Conversely, women with arthritis (AOR, 0.88; 95\% CI, 0.85-0.90), depression (AOR, 0.48; 95\% CI, 0.46-0.51), dementia (AOR, 0.68; 95\% CI, 0.63-0.72), diabetes (AOR, 0.79; 95\% CI, 0.77-0.81), hyperlipidemia (AOR,
0.91; 95\% CI, 0.88-0.93), and heart disease (AOR, 0.77 ; 95\% CI, 0.75-0.80) were less likely to receive GCC. Compared with women diagnosed at stage I, those diagnosed at stage II (AOR, 0.64; 95\% CI, 0.61-0.68) and stage III (AOR, 0.66; 95\% CI, 0.61- 
0.71) were less likely to receive GCC. Women with ER- and PR-negative tumors were more likely to receive GCC than those with positive tumors (AOR, 2.58; 95\% CI, 2.46-2.70 and AOR, 1.15; 95\% CI, $1.11-1.20$, respectively). Women with moderately and poorly differentiated tumors were more likely to receive GCC than those with highly differentiated tumors. Women residing in an area with a high density of mammography screening centers or those treated by an oncology surgeon only or both an oncology and a general surgeon were more likely to receive GCC than women treated by a general surgeon only. Women who were black (AOR, 0.60; 95\% CI, 0.58-0.62), Hispanic/Latino (AOR, 0.70; 95\% CI, $0.65-0.75)$, and of other races (AOR, 0.57; 95\% CI, 0.53-0.61) were less likely to receive GCC than white women.

\section{Receipt of Tests and Treatments}

Compared with women aged 66 to 74 years at diagnosis, those aged $\geq 75$ years were more than $40 \%$ less likely to receive GCC (AOR, 0.59; 95\% CI, 0.57-0.60) or AET (AOR, 0.63; 95\% CI, 0.61-0.65), almost $80 \%$ less likely to have any type of surgery (AOR, $0.22 ; 95 \% \mathrm{CI}, 0.20-0.24)$, approximately half as likely to have RT (AOR, 0.53; 95\% CI, 0.52-0.54), and approximately $61 \%$ less likely to have chemotherapy (AOR, 0.39; 95\% CI, 0.38-0.40) and 34\% less likely to experience an appropriate time to chemotherapy (AOR, 0.66; 95\% CI, 0.63-0.69) (Table 2).

\section{Discussion}

This study evaluated the extent to which older women with invasive breast cancer receive GCC in accordance with NCCN and ASCO evidencebased guidelines using the large, population-based SEER-Medicare database. Findings showed that only $40 \%$ received GCC, and rates were lowest among the oldest women (aged $\geq 80$ years). A recent study of women of all ages with breast cancer reported an $80 \%$ GCC rate, but also found that GCC decreased with age. ${ }^{29}$ The difference in rate of GCC reported between these studies is likely attributable to the difference in age composition of the study populations.

Interestingly, women between ages 70 and 74 years were more likely to receive GCC. A probable explanation for this finding is that RT is not recommended for a subset of women aged $\geq 70$ years with

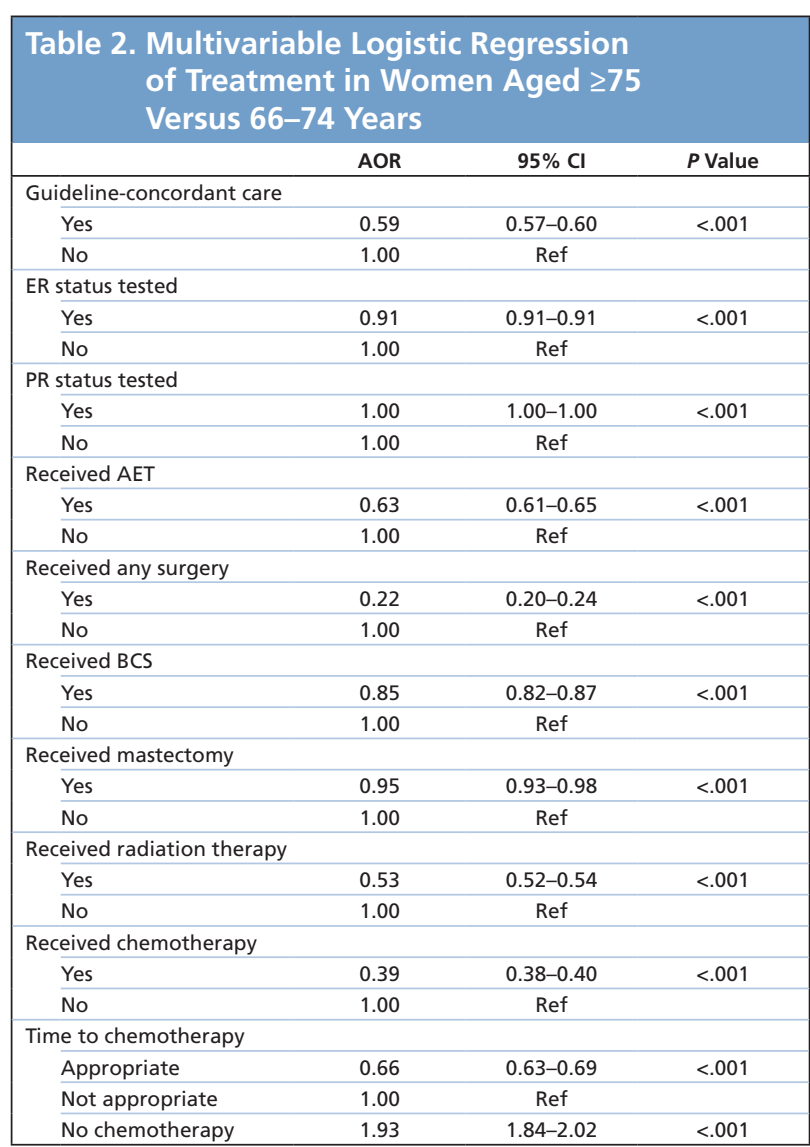

Abbreviations: AET, adjuvant endocrine therapy; $A O R$, adjusted odds ratio; $B C S$, breast-conserving surgery; ER, estrogen receptor; PR, progesterone receptor.

stage I breast cancer, and the decision to treat with chemotherapy is recommended to be made on a caseby-case basis for women aged $>70$ years. Therefore, many women $>70$ years of age who did not receive these treatments still received GCC by definition. However, even after these age-based treatment exemptions were considered in the definition of GCC, rates of GCC began to decrease for those aged $\geq 75$ years. Findings from comparisons made between women aged 66 to 74 and those aged $\geq 75$ years also show that women aged $\geq 75$ years were less likely to receive every type of treatment, even receipt of ER status testing and AET. This finding suggests that treatment decisions were made based on reasons other than clinical indications. As expected and consistent with previous research, rates of GCC were the lowest among women aged $>80$ years. ${ }^{9,17,28}$ However, a recent study reported no significant difference in overall survival between octogenarians and nonagenarians who did and did not receive adjuvant treatments for early-stage breast cancer. ${ }^{30}$ Therefore, the lower rates of 
Guideline-Concordant Care

GCC observed among the oldest age groups of women may be reasonable, considering individual patient circumstances. Moreover, because of functional status, quality of life, and life expectancy, oncologists often cite increasing age, with or without comorbidity, as the primary reason for use of less aggressive treatment. ${ }^{31-35}$ Patient preferences also play an important role in treatment decision-making, and older patients with breast cancer more frequently prefer to omit adjuvant treatments compared with younger patients. ${ }^{36}$ However, regardless of age or health, patients with hormone-negative and higher-grade tumors were more likely to receive GCC, a finding that has also been reported by previous research. ${ }^{17}$

The increasing prevalence of chronic conditions and multimorbidity among elderly patients with cancer presents additional treatment challenges, and is often associated with undertreatment. ${ }^{4,20,37}$ This study found that the presence of specific conditions, such as diabetes and heart disease, decreased the likelihood of GCC. Diabetes can decrease the likelihood of GCC by having a more severe impact on patient health, creating competing health demands and increasing the risk of treatment complications, intolerance, and adverse reactions, ${ }^{38-40}$ whereas certain other chronic conditions may increase the likelihood of GCC through increased contact with healthcare providers, without creating competing health demands and treatment complications. In fact, patients with breast cancer with a greater frequency of PCP visits were more likely to receive GCC.

This study has several strengths, including a comprehensive examination of the association between GCC among older women with breast cancer and health, clinical, oncology resource, and demographic characteristics using a large population-based data set. Complex algorithms were used to determine receipt of GCC by calculating the correct course of care according to each patient's tumor characteristics and comparing that with the actual care received.

However, several limitations should be kept in mind when interpreting the results of this study. This study did not measure completion of RT or chemotherapy, only the initiation of therapy. It also did not distinguish between the receipt of neoadjuvant and adjuvant chemotherapy. Neoadjuvant chemotherapy is given to some women to shrink larger tumors and provide an opportunity for BCS after clinical staging but before pathologic staging. Although tumor size was used to determine the need for postmastectomy RT, the number of positive lymph nodes was not. This study only accessed the presence of positive or negative nodes. Because the SEER program only began recording information about the status of HER2/neu breast cancer cases in 2011, this study did not assess treatment for HER2/neu-positive tumors. Nor does SEER-Medicare collect information regarding results of any Oncotype testing that may influence treatment choices.

\section{Conclusions}

A little more than half of older women received GCC for breast cancer, even after incorporating agebased considerations into the definition of GCC. Variations in GCC by age group likely reflect the differing definitions of GCC by age, given than women aged $\geq 75$ years were less likely to receive certain treatments. However, patients with more aggressive breast cancer characteristics were more likely to receive GCC. Given that older women represent close to half of all newly diagnosed breast cancers, and many are diagnosed at stages that require RT or chemotherapy, increasing rates of earlier-stage diagnosis and the development of less toxic treatments could help to improve GCC and survival while preserving quality of life.

\section{References}

1. Wickerham DL, O'Connell MJ, Constantino JP, et al. The half century of clinical trials of the National Surgical Adjuvant Breast and Bowel Project (NSABP). Semin Oncol 2008;35:522-529.

2. Gradishar WJ, Anderson BO, Balassanian R, et al. NCCN Clinical Practice Guidelines in Oncology: Breast Cancer. Version 3.2017. Accessed November 1,2017 . To view the most recent version of these guidelines, visit NCCN.org.

3. Popescu I, Schrag D, Ang A, Wong M. Racial/Ethnic and socioeconomic differences in colorectal and breast cancer treatment quality: the role of physician-level variations in care. Med Care 2016;54:780-788.

4. LeMasters TJ, Madhavan SS, Sambamoorthi U, Vyas AM. Disparities in the initial local treatment of older women with early-stage breast cancer: a population-based study. J Womens Health (Larchmt) 2017;26:735-744.

5. Camacho FT, Tan X, Alcalá HE, et al. Impact of patient race and geographical factors on initiation and adherence to adjuvant endocrine therapy in Medicare breast cancer survivors. Medicine (Baltimore) 2017;96:e7147.

6. Lautner M, Lin H, Shen Y, et al. Disparities in the use of breast-conserving therapy among patients with early-stage breast cancer. JAMA Surg 2015;150:778-786.

7. Wittayanukorn S, Qian J, Westrick SC, et al. Treatment patterns among breast cancer patients in the United States using two national surveys on 
LeMasters et al

visits to physicians' offices and hospital outpatient departments. Res Social Adm Pharm 2015;11:708-720.

8. Inwald EC, Ortmann O, Koller M, et al. Screening-relevant age threshold of 70 years and older is a stronger determinant for the choice of adjuvant treatment in breast cancer patients than tumor biology. Breast Cancer Res Treat 2017;163:119-130.

9. Mackey RV, Chandru Kowdley G. Treatment practices and outcomes of elderly women with breast cancer in a community hospital. Am Surg 2014;80:714-719.

10. Hughes K, Schnaper L, Berry D, et al. Lumpectomy plus tamoxifen with or without irradiation in women 70 years of age or older with early breast cancer. N Engl J Med 2004;351:971-977.

11. Hughes KS, Schnaper LA, Bellon JR, et al. Lumpectomy plus tamoxifen with or without irradiation in women age 70 years or older with early breast cancer: long-term follow-up of CALGB 9343. J Clin Oncol 2013;31:2382-2387.

12. VanderWalde N, Jagsi R, Dotan E, et al. NCCN Guidelines Insights: older adult oncology, Version 2.2016. J Natl Compr Canc Netw 2016;14:13571370 .

13. Muss HB, Woolf S, Berry D, et al. Adjuvant chemotherapy in older and younger women with lymph node-positive breast cancer. JAMA 2005;293:1073-1081.

14. Muss HB, Berry DA, Cirrincione CT, et al. Adjuvant chemotherapy in older women with early-stage breast cancer. N Engl J Med 2009;360:2055-2065.

15. Daugherty EC, Daugherty MR, Bogart JA, Shapiro A. Adjuvant radiation improves survival in older women following breast-conserving surgery for estrogen receptor-negative breast cancer. Clin Breast Cancer 2016;16:500 506.e2.

16. Reeder-Hayes K, Peacock Hinton S, Meng K, et al. Disparities in use of human epidermal growth hormone receptor 2-targeted therapy for early-stage breast cancer. J Clin Oncol 2016;10;34:2003-2009.

17. Schonberg M, Marcantonio E, Li D, et al. Breast cancer among the oldest old: tumor characteristics, treatment choices, and survival. J Clin Oncol 2010;28:2038-2045.

18. Luu C, Goldstein L, Goldner B, et al. Trends in radiotherapy after breastconserving surgery in elderly patients with early-stage breast cancer. Ann Surg Oncol 2013;20:3266-3273.

19. Tuttle TM, Jarosek S, Habermann EB, et al. Omission of radiation therapy after breast-conserving surgery in the United States. A population-based analysis of clinicopathologic factors. Cancer 2012;118:2004-2013.

20. Wollschläger D, Meng X, Wöckel A, et al. Comorbidity-dependent adherence to guidelines and survival in breast cancer-is there a role for guideline adherence in comorbid breast cancer patients? A retrospective cohort study with 2137 patients. Breast J 2018;24:120-127.

21. Howlander N, Noone AM, Krapcho M, et al, eds. SEER Cancer Statistics Review, 1975-2012, National Cancer Institute. Bethesda, MD. Available at: http://seer.cancer.gov/csr/1975_2011/. Accessed September 22, 2015.

22. Engels EA, Pfeiffer RM, Ricker W, et al. Use of Surveillance, Epidemiology, and End Results-Medicare data to conduct case-control studies of cancer among the US elderly. Am J Epidemiol 2011;174:860-870.

23. National Cancer Institute. Division of Cancer Control \& Population Sciences. Healthcare Delivery Research Program. SEER-Medicare: About the
Data Files. Available at: http://appliedresearch.cancer.gov/seermedicare/ aboutdata/. Accessed September 22, 2015.

24. U.S. Health Resources and Services Administration. Bureau of Health Professions. Area Resource File, 2009-2010 Release. Rockville, MD: U.S. Department of Health and Human Services; Fairfax, VA: Quality Resource Systems, Inc; 2010. Codebook: HE-001.

25. Carlson RW, Allred DC, Anderson BO, et al. Breast cancer. Clinical practice guidelines in oncology. J Natl Compr Canc Netw 2009;7:122-192.

26. Desch C, McNiff K, Schneider E, et al. American Society of Clinical Oncology/National Comprehensive Cancer Network quality measures. J Clin Oncol 2008;26:3631-3637.

27. Freedman RA, Virgo KS, He Y, et al. The association of race/ethnicity, in surance status, and socioeconomic factors with breast cancer care. Cancer 2010;117:180-189.

28. Working Group on Health Outcomes for Older Persons with Multiple Chronic Conditions. Universal health outcome measures for older person with multiple chronic conditions. J Am Geriatr Soc 2012;60:2333-2341.

29. Loggers ET, Buist DS, Gold LS, et al. Advanced imaging and receipt of guideline concordant care in women with early stage breast cancer. Int J Breast Cancer 2016;2016:2182985.

30. Merrill AY, Brown DR, Klepin HD, et al. Outcomes after mastectomy and lumpectomy in octogenarians and nonagenarians with early-stage breast cancer. Am Surg 2017;83:887-894.

31. Foster JA, Salinas GD, Mansell D, et al. How does older age influence oncologists' cancer management? Oncologist 2010;15:584-592.

32. Hurria A, Wong L, Villaluna D, et al. Role of age and health in treatment recommendations for older adults with breast cancer: the perspective of oncologists and primary care providers. J Clin Oncol 2008;26:5386-5392.

33. Crivellari D, Aapro M, Leonard R, et al. Breast cancer in the elderly. J Clin Oncol 2007;25:1882-1890.

34. Witherby SM, Muss HB. Managing early-stage breast cancer in your older patients. Oncology (Williston Park) 2006;20:1003-1012; discussion 10121013, 1017-1018.

35. Jones EL, Leak A, Muss HB. Adjuvant therapy of breast cancer in women 70 years of age and older: tough decisions, high stakes. Oncology (Williston Park) 2013;26:793-801.

36. Hamelinck VC, Bastiaannet E, Pieterse $\mathrm{AH}$, et al. A prospective comparison of younger and older patients' preferences for adjuvant chemotherapy and hormonal therapy in early breast cancer. Clin Breast Cancer 2016;16:379388 .

37. Wallwiener CW, Hartkopf AD, Grabe E, et al. Adjuvant chemotherapy in elderly patients with primary breast cancer: are women $\geq 65$ undertreated? J Cancer Res Clin Oncol 2016;142:1847-1853

38. Klepin HD, Pitcher BN, Ballman KV, et al. Comorbidity, chemotherapy tox icity, and outcomes among older women receiving adjuvant chemotherapy for breast cancer on a clinical trial: CALGB 49907 and CALGB 361004 (alliance). J Oncol Pract 2014;10:e285-292.

39. de la Morena Barrio P, Conesa MÁ, González-Billalabeitia E, et al. Delayed recovery and increased severity of paclitaxel-induced peripheral neuropathy in patients with diabetes. J Natl Compr Canc Netw 2015;13:417-423.

40. Gold HT, Makarem N, Nicholson JM, Parekh N. Treatment and outcomes in diabetic breast cancer patients. Breast Cancer Res Treat 2014;143:551-570. 